\title{
A Guide to the Use of Chain Aggregated NIPA Data
}

\author{
Karl Whelan \\ Division of Research and Statistics \\ Federal Reserve Board *
}

June, 2000

\begin{abstract}
In 1996, the U.S. Department of Commerce began using a new method to construct all aggregate "real" series in the National Income and Product Accounts (NIPA). This method employs the so-called "ideal chain index" pioneered by Irving Fisher. The new methodology has some extremely important implications that are unfamiliar to many practicing empirical economists; as a result, mistaken calculations with NIPA data have become very common. This paper explains the motivation for the switch to chain aggregation and then illustrates the usage of chain-aggregated data with three topical examples, each relating to a different aspect of how information technologies are changing the economy.
\end{abstract}

${ }^{*}$ Mail Stop 80, 20th and C Streets NW, Washington DC 20551. Email: kwhelan@frb.gov. I am grateful to Spencer Krane, David Lebow, Mike Palumbo, Jeremy Rudd, Dan Sichel, Sandy Struckmeyer, and Stacey Tevlin for comments on a previous draft. I would particularly like to thank Chris Ehemann of BEA for comments and for providing me with the derivation in the appendix. The views expressed are my own and do not necessarily reflect the views of the Board of Governors or the staff of the Federal Reserve System. 


\section{Introduction}

In 1996, the U.S. Department of Commerce began using a new method to construct all aggregate "real" series in the National Income and Product Accounts (NIPA). This method, now used to create real aggregates for flows such as GDP, consumption, and investment, as well as for stocks such as inventories and fixed capital, employs the so-called "ideal chain index" pioneered by Irving Fisher (1922). The new methodology has some extremely important implications for calculations with real NIPA series, which if ignored, can lead to incorrect conclusions concerning many important economy-wide phenomena. For example, suppose you are interested in how the "high-tech" sector of the economy has influenced aggregate output and investment as well as the average age of the capital stock. Some basic manipulations of NIPA data could lead one to the following conclusions: ${ }^{1}$

(1) Computer production has been the dominant factor in the recent improvement in U.S. real GDP growth: While real GDP expanded at the brisk pace of 3.8 percent per year over the period 1996-98, real output excluding the computer sector grew only 2.1 percent per year. (Calculation: Take the sum of real consumption, real investment, real government spending, and real net exports of computing equipment, subtract this sum from real GDP and then calculate the percentage change. See the upper panel of Figure 1.)

(2) Because of the rapid growth in investment in high-tech equipment, this category now accounts for more than half of all real equipment investment (Calculation: Take the ratio of real investment in information-processing equipment to total real equipment investment. See the middle panel of Figure 1.)

(3) The shift in the composition of investment away from structures and towards fasterdepreciating equipment such as computers has radically changed the average service life of the capital stock: The average depreciation rate for capital has more than doubled from 4 percent in 1960 to over 8 percent today. (Calculation: Take the real aggregate capital stock, $K_{t}$, and real aggregate investment, $I_{t}$, and re-arrange the perpetual inventory equation, $K_{t}=\left(1-\delta_{t}\right) K_{t-1}+I_{t}$, to give $\delta_{t}=\frac{I_{t}-\Delta K_{t}}{K_{t-1}}$. See the lower panel of Figure 1.)

Each of these statements, if true, should be of great interest to all economists. They paint a dramatic picture of how information technology is re-shaping the economy and ap-

\footnotetext{
${ }^{1}$ All data in this paper pre-date the October 1999 benchmark revision to the NIPAs and can be found in various editions of the Survey of Current Business. The capital stock data are from Department of Commerce (1998). Unless otherwise specified, the base year for all real expenditure series is 1992.
} 
Figure 1

\section{Three Misleading Calculations}
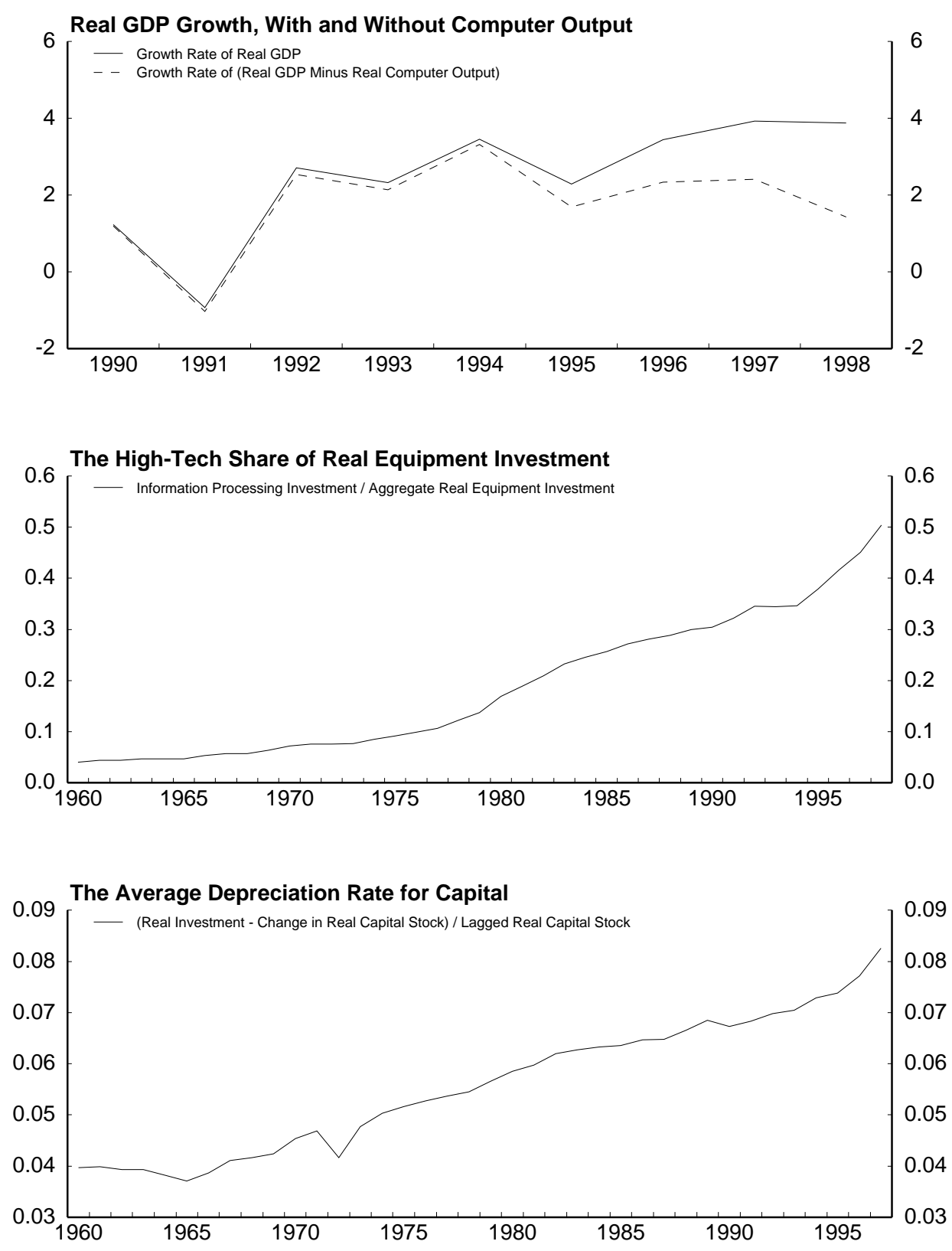
pear to provide evidence for the notion that technology is truly creating a "New Economy." However, the statements are, in fact, very misleading because the calculations on which they are based fail to take account of the methodology used to construct the relevant aggregates. A crucial feature of this chain aggregation methodology is that the real aggregate of $X$ and $Y$ will generally not equal the arithmetic sum of the real series for $X$ and $Y$. It is this lack of additivity that invalidates each of the calculations described above. Moreover, this feature applies most noticeably when we are dealing with categories undergoing large changes in relative prices, making it particularly tricky to assess the role of high-tech equipment, which has declined dramatically in price relative to other components of GDP.

This paper describes the NIPA's chain aggregation methodology and discusses some of its implications for empirical calculations. Perhaps because of its roots in the relative obscurity of index-number theory, perhaps because few economists spend time reading the Commerce Department's Survey of Current Business, or perhaps because of the usual scientific diffusion lags, many practicing empirical economists have had little or no exposure to the implications of chain aggregation for the analysis of macroeconomic data. As a result, mistaken calculations based on real NIPA data have become common in both academic publications and in the work of business economists. This paper is intended to help researchers avoid some of the common pitfalls of empirical work with chain-aggregated data and also to suggest some practical alternative strategies when using such data.

The paper begins with a general discussion of the reasons for the introduction of the chain aggregation methodology and then illustrates the implications of this procedure by re-visiting the three calculations just described. 


\section{Why Chain Aggregation?}

In the United States nominal GDP is constructed by the Commerce Department's Bureau of Economic Analysis (BEA) according to the expenditure method, using the textbook identity $Y=C+I+G+X-M$. In practice, BEA does not directly calculate these major aggregates but rather builds them up from a large number of disaggregated component series. $^{2}$

The purpose of the series known as "real GDP" is to tell us what part of the increase in nominal GDP is due to higher quantities, rather than higher prices. Naturally, the estimation of real GDP starts with a set of price indexes $\left(P_{i}(t)\right)$ for the disaggregated categories of goods and services. These price indexes are set equal to 1 in some base year, $b$. They are then combined with the nominal expenditure series $\left(Y_{i}(t)\right)$ to construct a set of quantity or real expenditure series, $Q_{i}(t)=\frac{Y_{i}(t)}{P_{i}(t)}$. The interpretation of $Q_{i}(t)$ is "the dollar value of year- $t$ 's expenditures on category $i$ had its price remained at its year- $b$ level"; this series is usually termed real year-b-dollar expenditures on category $i$.

These first steps are simple and intuitive. To use an obvious metaphor, they involve simply counting the quantity of apples produced and the quantity of oranges produced. The non-trivial part of calculating real GDP is creating a summary statistic that combines the quantity of apples produced and the quantity of oranges produced in an appropriate manner.

\section{Fixed-Weight Real GDP}

The traditional way to define real GDP has been to sum the real year- $b$ dollar expenditures for each category. The resulting series has the interpretation of "the value of period $t$ 's output had all prices remained at their year- $b$ level." Because this method values all quantities in terms of a fixed set of prices, as in a traditional Laspeyres index, it is known as a "fixed-weight" measure of real output. Until 1996, U.S. real GDP was constructed according to this method.

While the fixed-weight methodology has the advantage of simplicity and ease of interpretation, it also has a number of undesirable features. Most importantly, the growth rate of a fixed-weight measure real GDP depends on the choice of base year. Take 1998 as an

\footnotetext{
${ }^{2}$ See Seskin and Parker (1998) for a comprehensive discussion of the methododology used to construct GDP.
} 
example: The growth rate of fixed-weight real GDP in this year was 4.5 percent if we use 1995 as the base year; using 1990 prices it was 6.5 percent; using 1980 prices it was 18.8 percent; and using 1970 prices, it was a stunning 37.4 percent! ${ }^{3}$

The reason we get higher growth rates for real GDP when using earlier base years is the well-known problem of "substitution bias" associated with fixed-weight indexes. Categories with declining relative prices tend to have faster growth in quantities; the further back the base year the larger is the weight on these fast-growing categories and so the faster is the growth rate of real output. ${ }^{4}$ Similarly, for a given base year, the growth rate of a fixedweight quantity index tends to increase over time as the output bundle becomes increasingly expensive when measured in terms of the base year's prices. This problem became more severe after the mid-1980s because of BEA's decision to measure computer prices according to the hedonic method pioneered by Zvi Griliches (1961). This approach revealed enormous declines in the quality-adjusted price of computing power and the introduction of these prices accentuated the tendency of fixed-weight GDP to accelerate over time.

To make growth rates for recent years less subject to substitution bias, BEA periodically "re-based" the fixed-weight measures of GDP by moving the base year forward. However, while routinely updating the base year may improve estimates of recent real GDP growth, it makes estimates from earlier years worse and leads to a pattern of predictable revisions to real output growth. In any case, beyond the problems of substitution bias and predictable revisions to growth, fixed-weight measures of real GDP suffer from a basic interpretation problem: Why should we care about how the value of output would have grown had all prices remained at their year- $b$ level? What's so special about year $b$ ? Obviously, 1998's increase in the quantity of quality-adjusted computer output would have been enormously

\footnotetext{
${ }^{3}$ These figures actually understate the true pattern. BEA still calculates fixed-weight estimates of real GDP; this series was last published as Table 8.27 in Department of Commerce (1998). BEA's (unpublished) estimate of 1992-based fixed-weight real GDP growth for 1998 was 6.6 percent. The method I used to do these calculations gives 5.5 percent when using 1992 weights and shows less acceleration. The reason for the discrepancy is the level of disaggregation. In constructing the figures reported here, I divided output into a large number of disaggregated expenditure categories and constructed real series for each according to various base years. However, I did not use as fine a level of disaggregation as that used by BEA to construct the real GDP so, for reasons that will become apparent later (some of these disaggregated series are actually chain aggregates) these figures actually underestimate the tendency of fixed-weight GDP to accelerate.

${ }^{4}$ For instance, much of the recent research on the problems with the Consumer Price Index as a measure of the cost-of-living has focused on the substitution bias caused by the fixed-weight nature of this index. See Boskin et al (1998) and Diewert (1998).
} 
valuable in 1992, but it is also obvious that we would never have seen this increase without the declines in quality-adjusted prices since 1992, making the implied counterfactual a little odd.

\section{A Solution: Chained Indexes}

An alternative to using a fixed set of prices to evaluate real GDP is to continually update the prices used to calculate the growth rate of real output, defining the level of real GDP by setting it equal to nominal GDP in some base year and then "chaining" forward and backward from the base year using these growth rates. Estimates of real GDP growth from this chain aggregation method never have to rely on potentially irrelevant price structures that prevailed many years before or after the period in question; they also have the great advantage of being independent of the choice of base year.

To address the problems with its fixed-weight measures, in 1996 BEA began calculating real GDP and all other published real aggregates according to a chain index formula. Specifically, BEA now calculates the growth rate of real aggregates according to the socalled "ideal" chain index popularized by Irving Fisher (1922):

$$
Q(t)=Q(t-1) \sqrt{\frac{\sum_{i=1}^{n} P_{i}(t) Q_{i}(t)}{\sum_{i=1}^{n} P_{i}(t) Q_{i}(t-1)} \times \frac{\sum_{i=1}^{n} P_{i}(t-1) Q_{i}(t)}{\sum_{i=1}^{n} P_{i}(t-1) Q_{i}(t-1)}}
$$

The gross growth rate of the real aggregate at time $t$ is calculated as a geometric average of the gross growth rates of two separate fixed-weight indexes, one a Paasche index (using period $t$ prices as weights) and the other a Laspeyres index (using period $t-1$ prices as weights. $)^{5}$

The Fisher index approach has a number of important advantages over the old fixedweight method. Because the growth rate of the Fisher chain aggregate at time $t$ depends only on the prices and quantities prevailing at times $t$ and $t-1$, there is no problem with substitution bias. As a result, there is no need to continually revise the growth rate of real GDP by updating the base year. ${ }^{6}$ This advantage has been particularly important in recent

\footnotetext{
${ }^{5}$ See Landefeld and Parker $(1995,1998)$ for BEA's official position on the change in methodology. See also Vavares, Prakken, and Guirl (1998) for an excellent discussion of many of the issues covered in this section.

${ }^{6}$ Another attractive feature of the Fisher aggregation method is that the GDP deflator (ratio of nominal
} 
years because the combination of rapidly declining computer prices and large increases in nominal spending on computers would have made fixed-weight measures of GDP growth particularly subject to substitution bias. Prior to the adoption of the chain aggregation procedure, BEA's practice had been to move the base year forward every five years; as our example comparing 1990-based and 1995-based fixed-weight measures showed, such a procedure would have resulted in predictable revisions to published real GDP growth for recent years of over two percentage points. By preventing the need for such large revisions, the move away from a fixed-weight approach has avoided a problem that would have greatly complicated the interpretation of the recent macroeconomic performance of the U.S. economy.

\section{The Drawback: Non-Additivity}

Clearly, then, the chain aggregation approach greatly alleviates the interpretational problems associated with the previous fixed-weight measures of real output growth. Nevertheless, few improvements come without some cost, and the principal problem with chain aggregation is that it makes the interpretation of the level of real output more complex. BEA's procedure has been to set real chain aggregates equal to their nominal counterparts in the same base year, $b$, used to define the published real series for the expenditure components (the $\left.Q_{i}(t) \mathrm{s}\right)$. The published levels of real aggregates are then described as being in terms of "chained year- $b$ dollars." These series need to be interpreted very carefully.

The level of chain-aggregated real GDP reflects only the cumulation of period-by-period growth rates, where the growth rates are determined by continuously updated price weights. So, the "chained year- $b$ dollar" terminology merely reflects the base year chosen to equate real and nominal output. However, this choice of base year is arbitrary and has no effect on the measure of the growth rate of real output. More importantly, this measure of the level of real output cannot be interpreted as the cost of output had all prices remained fixed at their year- $b$ levels. This means that, by definition, "chained year- $b$ dollar" real GDP does not equal the simple sum of the real year- $b$ dollar series of its individual components.

This non-additivity may seem a little mysterious to those used to the fixed-weight

to real GDP) obtained from this real output series is itself a Fisher ideal index, based on moving quantity weights. Thus, this approach provides a conceptually unified treatment of aggregate prices and quantities. See the celebrated contribution of Diewert (1976) for a detailed treatment of the properties of so-called "superlative" index numbers, a broad class that includes Fisher's ideal index. 
approach, but its pattern is actually quite simple and intuitive. Note from equation (1) that the growth rate of a chain aggregate will be the same as that of a fixed-weight aggregate if relative prices do not change. But if relative prices are changing, then those products that decline in relative price will have a smaller impact on chained GDP growth after the base year and a larger impact prior to the base year. As quantities of these products tend to grow fastest this means that, in general, chain aggregates will grow slower than their fixed-weight counterparts after the base year, and faster prior to the base year. Because both methods equate real and nominal output in the base year, the difference between the levels of chain-weight and fixed-weight GDP (sometimes rather uninformatively labeled a "chain-weighting residual") follows an inverse-U shape, equalling zero in the base year and becoming more negative as we move away from the base year in both directions.

It is the lack of additivity of the Fisher chain formula that invalidates each of the calculations discussed in our introduction. Let us now consider each in turn.

\section{Addition and Subtraction}

Turn to our first example, the calculation of real output growth for the non-computer sector for 1996-98. Recall that we first calculated real computer output as the arithmetic sum of real consumption, real investment, real government spending, and real net exports of computing equipment and then subtracted this sum from real GDP. ${ }^{7}$

When using chain-aggregated data, both these steps are incorrect. The first step - simple addition of the separate real expenditure series for computers - is incorrect because the price deflators differ for the separate computer series, so straight addition of the real expenditure series will fail to account for the effect of relative price shifts within the computer bundle on chain-aggregated GDP. However, because the relative price movements between these computer categories are small, this error is fairly harmless; in other cases, where relative price shifts are important, direct addition of real expenditure series will be a more significant mistake.

The second step - estimating the level of non-computer real output by subtracting real

\footnotetext{
${ }^{7}$ Technically, this computer series is an attempt to measure real final sales of the computer industry rather than real output because the investment series does not include the inventory investment of the computer industry, which is not published by BEA.
} 
computer output from real GDP - is a far more serious error. Computer prices fell rapidly relative to other components of GDP after 1992 (the base year for these calculations), so increased real computer output had a much smaller effect on chain-aggregated real GDP over 1996-98 than it would if a fixed-weight methodology been used. As a result, subtracting real computer output from chain-aggregated real GDP (as though this had been constructed from a fixed-weight method) will understate growth in the non-computer sector.

What is the proper way to do this calculation? If $Y$ is a chain aggregate of $n$ components $\left(X_{1}, X_{2}, \ldots, X_{n}\right)$ then $Y$ will also be (arbitrarily close to) a chain aggregate of $X_{1}$ and the chain aggregate of $\left(X_{2}, \ldots, X_{n}\right)$. So, the only intuitive meaning of "the real aggregate for $Y$ excluding $X_{1}$ " is the chain aggregate of $\left(X_{2}, \ldots, X_{n}\right)$. This means that, in principle, since real GDP is a chain aggregate of a large number of categories, to calculate the real output of the non-computer sector we need to re-aggregate but this time excluding the components of computer output. In practice, however, most researchers will not have access to data for all the categories that BEA uses to construct real GDP. And ideally, even if $Y$ is a chain aggregate of $n$ components, we would like only to use information on $Y$ and $X_{1}$ when calculating the real growth rate for $Y$ excluding $X_{1}$. Thankfully, some methods are available that will usually provide good approximations to the results that would be obtained using BEA's full level of detail. For example, a "chain-subtraction" procedure that constructs a Fisher index using the real series for $Y$ and $-X_{1}$ as the quantities and the deflators for $Y$ and $X_{1}$ as the prices will generally produce a new series that is almost identical to that obtained from chain aggregating $X_{2}, \ldots, X_{n}{ }^{8}$

A simpler, although somewhat less precise, method uses the Tornqvist index approximation to the Fisher formula. The growth rate of a Tornqvist index is a weighted average of the growth rates of its components, where the weights are averages of nominal shares in the current and previous periods. ${ }^{9}$ This index provides a very close approximation to the Fisher index. Suppose, then, that we know the real and nominal series for a Fisher

\footnotetext{
${ }^{8}$ The principal case in which this approximation technique does not work well is when our disaggregated series include separate series on the change in inventories. The published chain-aggregate estimates for the change in inventories are actually changes in Fisher indexes of inventory stocks, as opposed to Fisher indexes of changes in stocks, which cannot be computed because the Paasche and Laspeyres indexes can switch sign, requiring a negative square root in the Fisher calculation.

${ }^{9}$ Technically, the Tornqvist index weights log-differences as opposed to growth rates but the differences between these two types of series over short periods are usually very small. Again, see Diewert (1976) for more on the properties of this index.
} 
chain-aggregate, $Y$, and one of its components, $X$, and we want to construct a time series for real $Y$ excluding $X$ (call this series $Z$.) Using the Tornqvist formula, we know that the following is approximately true:

$$
\frac{\Delta Y_{t}}{Y_{t-1}}=\theta_{t} \frac{\Delta X_{t}}{X_{t-1}}+\left(1-\theta_{t}\right) \frac{\Delta Z_{t}}{Z_{t-1}}
$$

where $\theta_{t}$ is the average of the ratio of nominal $X$ to nominal $Y$ in periods $t$ and $t-1$. This equation can be re-arranged to arrive at an estimate of the growth rate of $Z$ that will be close to that obtained from re-aggregating the components of $Z$ using the Fisher formula. The level of $Z$ can then be constructed by setting it equal to the nominal series for $Y$ minus the nominal series for $X$ in the base year and chaining forward and back from the base year using the calculated growth rate. ${ }^{10}$

Applying either of these methods reveals that real GDP excluding computer output grew 3.2 percent on average over 1996-98, compared to 3.8 percent growth for total real GDP. Recall that the series obtained from summing the real components of computer output and subtracting from real GDP grew only 2.1 percent per year over this period. Thus, the spectacular growth in real computer output over this period (60 percent per year) added 0.6 percent per year to aggregate output growth, not the 1.7 percent implied by the incorrect calculation.

Of course, this example was not chosen at random. Chain- and fixed-weight indexes differ because of relative price changes, so the mistake of treating chain-weighted series as though they are fixed-weight series will prove most misleading when the calculations involve categories with large relative price movements. This means that the categories for which we have to be most aware of the implications of chain aggregation are those upon which the most attention is currently being focused, namely, computers and other types of high-tech equipment, which have declined dramatically in price relative to other types of output.

\footnotetext{
${ }^{10}$ In general, however, this method is inferior to the "chain-subtraction" approach because it cannot handle aggregate inventory investment as a component. This series switches sign and so a growth rate cannot be calculated.
} 


\section{Real Shares}

By now, it should be fairly obvious what is wrong with the second statement above, that information-processing equipment now accounts for more than half of aggregate real equipment investment. This statement was based on the ratio of real 1992-dollar investment in information-processing equipment to the published (chain) aggregate series for real 1992dollar equipment investment. ${ }^{11}$ However, while this ratio can be used to illustrate how the numerator has grown relative to the denominator, the level of this series cannot be interpreted as a share. The problem is that this "share" is not a share at all because the sum of these ratios across all expenditure categories does not equal one!

The aggregate series for real equipment investment is a chain aggregate of 24 component series. Summing the 1998 values for the 24 real 1992-dollar equipment series we get a figure 15 percent larger than the chain-aggregate. Of course, the two series are equal in the base year 1992, but moving back in time prior to the base year, the sum of the 24 components again gets continually larger relative to the chain-aggregate: For 1960, the sum of the component series is 46 percent higher than the chain-aggregate. This non-additivity explicitly invalidates the interpretation of the ratio of real investment in information-processing equipment to aggregate real equipment investment as being a share. But the problem with the share interpretation goes beyond the fact that the ratios do not sum to one. Information-processing equipment has been declining in price relative to the other components of equipment investment, so the growth in the quantity of this type of equipment has less impact on the growth in the aggregate than it would in a fixed-weight calculation. So, not only do these real ratios not sum to one, they may also be misleading indicators of the contribution of the numerator series to the growth in the denominator, particularly if the comparisons are made over long periods.

The inability to calculate real shares with chain-aggregated data could be viewed as a disadvantage. It is important to note, though, that even when using the fixed-weight methodology, real shares are an elusive concept. The ratio of real year- $b$ dollar output of product $i$ to real year- $b$ dollar fixed-weight GDP answers the following question: "Suppose all prices had remained at year- $b$ 's level; what proportion of the total value of this year's output would have been accounted for by the output of product $i$ ?" Clearly, the answer

\footnotetext{
${ }^{11}$ Greenwood and Jovanovic (1999) cite the rise in this ratio as evidence of the increasing importance of high-tech investment.
} 
depends on the base year chosen. In 1998, investment in information-processing equipment was 48 percent of a 1992-based fixed-weight measure of real aggregate equipment investment; because this type of equipment was extremely expensive in 1960, the corresponding share of a 1960-based measure was 85 percent. Ultimately, the rapid decline in prices for high-tech goods makes neither of these figures particularly meaningful.

That real shares are a problematic concept, particularly with chain-weighted data, may be a little frustrating for those used to performing such calculations. Usually, however, one can answer the question at hand by using one of the following two methods.

Compute Nominal Shares: While inflation has an adverse effect on the use of nominal time series for certain tasks, that doesn't mean they can't ever be used. In fact, if the question is about resource allocation, then nominal shares usually give an intuitive answer. For instance, suppose we want to know what proportion of output is being allocated towards capital investment. The ratio of nominal investment to nominal GDP gives a much cleaner answer than the corresponding real ratio: The nominal ratio tells us very simply what fraction of each dollar spent is allocated to purchasing investment goods.

Nominal shares can also help correct some misleading impressions that real variables may give about the changing role of information technology in the economy. While the (essentially meaningless) ratio of real 1992-dollar information-processing investment to aggregate real equipment investment (the middle panel of Figure 1) goes from 0.07 in 1970 to 0.50 in 1998, the corresponding nominal ratio only changes from 0.22 to 0.34 over the same period. This shows that, in terms of actual dollars spent, the increase in the role of information technology has been more modest than one might think. ${ }^{12}$ Information technologies may have been extremely expensive in 1970, with large nominal expenditures buying small amounts of computing power; nevertheless, many firms were aware of the power of these technologies and willing to allocate significant fractions of their capital spending budgets to them.

\footnotetext{
${ }^{12}$ As a result of the introduction of software as a capital asset in the October 1999 comprehensive revision, the most recent NIPA data show this share increasing from 0.24 in 1970 to 0.44 in 1998.
} 
Compute Contributions to Growth: Sometimes, we want to calculate a "real share" for a particular category to show that it has contributed more (or less) to the growth of a real aggregate than other categories. However, there are other ways to do this calculation for chain aggregates. For example, it can be shown that the growth rate of a chain aggregate can be expressed as

$$
\frac{\Delta Q(t)}{Q(t-1)}=\sum_{i=1}^{n} \frac{\left(P_{i}(t-1)+P_{i}(t) / \Pi(t)\right) \Delta Q_{i}(t)}{\left[\sum_{i=1}^{n}\left(P_{i}(t-1)+P_{i}(t) / \Pi(t)\right) Q_{i}(t-1)\right]}=\sum_{i=1}^{n} c_{i}(t)
$$

where $\Pi(t)$ is the aggregate Fisher price index in period $t$ relative to period $t-1$ (that is, the gross growth rate of the GDP deflator at time $t$.) This equation decomposes the growth rate of a chain aggregate into the contributions due to the change in the quantity of each component (the $\left.c_{i}(t) \mathrm{s}\right)$. The derivation of this formula is provided in an appendix.

These contributions to growth are very useful because they can correct the potentially misleading impressions given by ratios of real expenditure series; for instance, if the relative price of a product is falling, then the ratio of real expenditures for the product to real GDP could be accelerating while its contribution to real GDP growth is not changing. Contribution series are also easily available because BEA now publishes them for all major categories in the Survey of Current Business. So, while we may not be able to add up the $Q_{i}(t)$ s to obtain the level of the real aggregate, we can easily add the $c_{i}(t) Q(t-1)$ terms to obtain the change in the aggregate. ${ }^{13}$

Because we know that $\Delta Q(t)=\sum_{i=1}^{n} c_{i}(t) Q(t-1)$, this method can also be used to calculate the contribution of a particular category to the change in a real chain aggregate over longer periods of time. For instance, returning to our information-processing example, one can use this method to show that increases in real investment in information-processing equipment accounted for 51 percent of the increase in real aggregate equipment investment between 1960 and 1980, and that this contribution moved up to 63 percent for 1980 to 1998. So, while the simple real ratio quoted above is somewhat misleading, it is still true that increased real spending on information-processing equipment has accounted for most of the growth in aggregate real equipment investment since 1960.

\footnotetext{
${ }^{13}$ Technically, the quarterly contributions published by BEA do not correspond exactly to equation (3). This equation is an exact formula for the actual percentage change in a Fisher aggregate while BEA publishes quarterly changes at an annualized percentage rate. Thus, the formula is adjusted slightly to arrive at the published contributions.
} 


\section{The Average Depreciation Rate}

Our first two examples involved assessing the influence of disaggregated components on the behavior of real expenditure aggregates. But these are not the only calculations requiring care when using chain-aggregated data. Generally speaking, most calculations based on ratios of chain-weighted real series are problematic.

Consider the third statement above, about the average depreciation rate for the capital stock. This parameter features in most empirical work on dynamic general equilibrium models and is usually calibrated as described above by re-arranging a simple "law of motion" or perpetual inventory equation with real aggregates for investment and the capital stock. ${ }^{14}$ Using this method, we concluded that the average depreciation rate has more than doubled since 1960, from 4.0 percent to 8.3 percent in 1997 (see the bottom panel of Figure 1.) However, it turns out that performing this calculation with chain aggregates gives a misleading picture.

The NIPA capital stock used in this calculation is a chain aggregate of stocks of a large number of underlying categories of equipment and structures. These are constructed according to a perpetual inventory equation $\left(K_{t}^{j}=\left(1-\delta_{j}\right) K_{t-1}^{j}+I_{t}^{j}\right)$ with separate constant depreciation rates for each category. ${ }^{15}$ Nominal stocks are defined for each category on a "current-dollar replacement value" basis and are obtained by inflating each real stock by the relevant current-period investment deflator.

Obviously, one can create fixed-weight aggregates from these real capital stock and investment series by simple addition $\left(K_{t}^{f w}=\sum_{j=1}^{n} K_{t}^{j}\right.$ and $I_{t}^{f w}=\sum_{j=1}^{n} I_{t}^{j}$.) Note also that the depreciation rate backed out from a perpetual inventory equation using $K_{t}^{f w}$ and $I_{t}^{f w}$ is a weighted average of the underlying depreciation rates, where the weight for each category is its share in the fixed-weight capital stock. In other words,

$$
K_{t}^{f w}=\left(1-\delta_{t}^{f w}\right) K_{t-1}^{f w}+I_{t}^{f w} \quad \delta_{t}^{f w}=\sum_{j=1}^{n} \frac{\delta_{j} K_{t-1}^{j}}{K_{t-1}^{f w}}
$$

When using chain-aggregated investment and capital stocks, however, this intuition does

\footnotetext{
${ }^{14}$ For instance, Cooley and Prescott (1995) is a commonly cited paper on calibration of dynamic stochastic general equilibrium models that uses this method. Of course, the capital stocks used in that paper were fixed-weight aggregates. The problem discussed here concerns applying this method to the current published chain-aggregated capital stocks.

${ }^{15}$ See Katz and Herman (1997) for a full discussion of the NIPA capital stock methodology.
} 
not hold. Re-arranging a perpetual inventory equation with chain aggregates, the resulting "depreciation rate" can no longer be interpreted as a weighted average of the underlying rates. To see why, consider a simple steady-state example.

Suppose there are two types of capital, $A$ and $B$, which depreciate at the same rate, $\delta$. Type- $A$ capital falls in price relative to type- $B$ at a steady pace and demand for $A$ is unit-elastic. This means that the real capital stock and real investment for $A$ grow faster than their type- $B$ counterparts but that the $A$ 's shares in the nominal capital stock and in nominal investment are constant. Re-arranging the perpetual inventory equation tells us that faster capital stock growth for $A$ implies the ratio of real investment to real capital stock is higher for $A$ than for $B$. By definition, this implies the ratio of nominal investment to nominal capital stock is greater for $A$ than for $B$. This also means the share of type $A$ in nominal investment is higher than its share in the nominal capital stock.

Algebraically, these steps can be expressed as follows:

$$
\frac{I_{t}^{A}}{K_{t}^{A}}>\frac{I_{t}^{B}}{K_{t}^{B}} \Rightarrow \frac{P_{t}^{A} I_{t}^{A}}{P_{t}^{A} K_{t}^{A}}>\frac{P_{t}^{B} I_{t}^{B}}{P_{t}^{B} K_{t}^{B}} \Rightarrow \frac{P_{t}^{A} I_{t}^{A}}{P_{t}^{B} I_{t}^{B}}>\frac{P_{t}^{A} K_{t}^{A}}{P_{t}^{B} K_{t}^{B}}
$$

Recalling our discussion above about the Tornqvist index, we know that Fisher chain aggregates approximately weight the growth rates of their component series by their nominal shares. Because investment and capital grow faster for $A$ than for $B$ and because the share of $A$ in nominal investment is bigger than its share in the nominal capital stock, this implies that the chain-aggregate for real investment will always grow faster than the chain aggregate for the real capital stock.

Now suppose we attempt to implement the perpetual inventory formula using the chain aggregates for investment and the capital stock, solving for $\delta_{t}^{c w}=\frac{I_{t}^{c w}}{K_{t-1}^{c c w}}-g_{t}^{c w}$, where $g_{t}^{c w}$ is the growth rate of the chain-aggregated capital stock (which is constant in this example.) Even though both types of capital depreciate at the constant rate $\delta$, the estimated "depreciation rate", $\delta_{t}^{c w}$, will get larger each period because $I^{c w}$ always grows faster than $K^{c w}$. More generally, if we allowed the two types of capital to have different rates of depreciation, then $\delta_{t}^{c w}$ would only be a weighted average of the underlying depreciation rates in the base year; moving away from the base year this measure could eventually be higher or lower than each of the underlying depreciation rates. ${ }^{16}$

\footnotetext{
${ }^{16}$ Tevlin and Whelan (2000) show that this effect of chain aggregation is important for models of equipment investment that use the traditional $\frac{I_{t}}{K_{t-1}}$ formulation. Without a correction for the effects of chain
} 
Obviously, this example is somewhat artificial but it captures an important aspect of reality. The shares in nominal investment of those components that are growing fastest in real terms, such as computing equipment, are indeed significantly higher than their shares in the nominal capital stock, so the pattern described in this example is likely to be empirically important. A better way to measure the average depreciation rate is to take a weighted average of depreciation rates of the underlying categories using shares in the nominal capital stock as weights; this is appropriate because the growth in the aggregate real capital stock is approximately a nominal-share weighted average. This method confirms that the calculation using chain aggregates is misleading: It shows a much more modest increase in the average pace of depreciation, from 5.8 percent in 1960 to 7.0 percent in $1997 . .^{17}$

This example illustrates a general principle: Ratios of real chain-aggregated series usually do not make sense. While intuition may tell us that the aggregate real capital stock is the sum of aggregate real investment and depreciated aggregate real capital from last period, this identity actually only holds at a disaggregated level. In fact, the chain aggregate for investment can grow faster than the chain aggregate for the capital stock ad infinitum, with the level of aggregate real investment potentially becoming larger than the level of the aggregate real capital stock. ${ }^{18}$

\section{Conclusions}

The adoption of the Fisher chain procedure for creating real aggregates has removed many of the anomalies previously associated with U.S. NIPA data on aggregate real stocks and flows. However, it has also introduced some complexities into macroeconomic data analysis and led to a proliferation of mistaken calculations by business and academic economists. This paper has used some simple examples to illustrate the problems that can arise when using chain-aggregated data and to suggest some alternative ways of manipulating these data.

aggregation on this variable, aggregate models with this specification will consistently under-predict out of sample.

${ }^{17}$ The disaggregated capital stock and investment data used for this calculation are from a CD-ROM that can be ordered from BEA at http://www.bea.doc.gov/bea/uguide.htm.

${ }^{18}$ In practice, the periodic re-basing of the NIPAs would probably prevent this from ever happening. 
One important conclusion is that researchers need to be particularly aware of the implications of chain aggregation when assessing the role of information technologies in the U.S. economy. Prices for high-tech products have fallen rapidly relative to other components of GDP and chain aggregates differ most from their traditional fixed-weight counterparts when there are large shifts in the relative prices of their components. Without taking care to handle aggregate series in a manner consistent with their construction, it is easy to mistakenly assign too important a role to the high-tech sector in the recent behavior of investment and output. This is not to say that this sector has been unimportant in the U.S. economy's recent performance. In fact, using growth accounting techniques, Jorgenson and Stiroh (2000), Oliner and Sichel (2000), and Whelan (2000) have all concluded that the high-tech sector has been central to the acceleration in productivity since the mid-1990s.

Finally, I should note that the calculations in this paper using 1992-based series are a little out of date. These data were current in September 1999 but since then, BEA has published a comprehensive revision to the NIPAs. This revision incorporated some definitional changes such as the inclusion of software as capital asset and also updated the base year for all real series to $1996 .{ }^{19}$ A consequence of moving the base year forward is that if one performs the incorrect calculations described in this paper using the most current NIPA data, the errors for years close to 1996 will now be smaller than those described in this paper using the 1992-based data. However, the inclusion of software (prices for which have been declining) and the ongoing attempts to better capture quality improvements in published price series make it likely that relative price movements will become more important in the NIPAs in future. Thus, as we move further away from the new base year, calculations using real NIPA data will have to account for chain aggregation because future mistakes may prove even more misleading than those discussed here.

\footnotetext{
${ }^{19}$ See Moulton, Parker, and Seskin (1999) for discussion of the changes in the comprehensive revision.
} 


\section{References}

[1] Boskin, Michael, Ellen Dulberger, Robert Gordon, Zvi Grilliches, and Dale Jorgenson (1998) . "Consumer Prices, the Consumer Price Index, and the Cost of Living." Journal of Economic Perspectives, 12, Winter, 3-26.

[2] Cooley, Thomas and Edward Prescott (1995). "Economic Growth and Business Cycles," in Thomas Cooley (ed.) Frontiers of Business Cycle Research, Princeton: Princeton University Press.

[3] Diewert, W. Erwin (1976). "Exact and Superlative Index Numbers." Journal of Econometrics, 4, 115-145.

[4] Diewert, W. Erwin (1998). "Index Number Issues in the Consumer Price Index." Journal of Economic Perspectives, 12, Winter, 47-58.

[5] Fisher, Irving (1922). The Making of Index Numbers, Boston: Houghton-Mifflin.

[6] Greenwood, Jeremy and Boyan Jovanovic (1999). "The Information-Technology Revolution and the Stock Market." American Economic Review (Papers and Proceedings), 89, No. 2, 116-122.

[7] Griliches, Zvi (1961). "Hedonic Price Indexes for Automobiles: An Econometric Analysis of Quality Change," reprinted in Zvi Grilliches (ed.) Price Indexes and Quality Change, 1971, Cambridge: Harvard University Press.

[8] Jorgenson, Dale and Kevin Stiroh (2000). "Raising the Speed Limit: U.S. Economic Growth in the Information Age." Brookings Papers on Economic Activity, forthcoming.

[9] Katz, Arnold and Shelby Herman (1997). "Improved Estimates of Fixed Reproducible Tangible Wealth, 1929-95." Survey of Current Business, May, 69-92.

[10] Landefeld, Steven and Robert Parker (1995). "Preview of the Comprehensive Revision of the National Income and Product Accounts: BEA's New Measures of Output and Prices." Survey of Current Business, July, 31-38.

[11] Landefeld, Steven and Robert Parker (1998). "BEA's Chain Indexes, Time Series, and Measures of Long-Term Economic Growth." Survey of Current Business, May, 58-68. 
[12] Moulton, Brent, Robert Parker, and Eugene Seskin (1999). "A Preview of the 1999 Comprehensive Revision of the National Income and Product Accounts: Definitional and Classificational Changes." Survey of Current Business, August, 7-20.

[13] Moulton, Brent and Eugene Seskin (1999). "A Preview of the 1999 Comprehensive Revision of the National Income and Product Accounts: Statistical Changes." Survey of Current Business, October, 6-17.

[14] Oliner, Stephen and Daniel Sichel (2000). "The Resurgence of Growth in the Late 1990s: Is Information Technology the Story?" Journal of Economic Perspectives (forthcoming).

[15] Vavares, Chris, Joel Prakken, and Lisa Guirl (1998). "Macro Modeling with ChainType GDP." Journal of Economic and Social Measurement, 24(2), 123-42.

[16] Seskin, Eugene and Robert Parker (1998). "A Guide to the NIPA's." Survey of Current Business, March, 26-68.

[17] Tevlin, Stacey and Karl Whelan (2000). "Explaining the Investment Boom of the 1990s." Federal Reserve Board, Finance and Economics Discussion Series Paper No. 2000-11, (http://www.bog.frb.fed.us/pubs/feds/2000/index.html).

[18] U.S. Dept. of Commerce, Bureau of Economic Analysis (1998). "National Income and Product Accounts Tables." Survey of Current Business, August, 36-118.

[19] U.S. Dept. of Commerce, Bureau of Economic Analysis (1998). "Fixed Reproducible Tangible Wealth in the United States: Revised Estimates for 1995-97 and Summary Estimates for 1925-97." Survey of Current Business, September, 36-46.

[20] Whelan, Karl (2000). "Computers, Obsolescence, and Productivity." Federal Reserve Board, Finance and Economics Discussion Series Paper No. 2000-6, (http://www.bog.frb.fed.us/pubs/feds/2000/index.html). 


\section{A Deriving the Contributions to Growth Formula}

The formula for the contribution of a category to the growth in a Fisher chain aggregate, shown in the text as equation (3), can be derived as follows.

Using the same notation as in the text, proving that equation (3) holds requires showing that if

$$
G(t)=\frac{Q(t)}{Q(t-1)}=\frac{\sum_{i=1}^{n}\left(P_{i}(t-1)+P_{i}(t) \lambda(t)\right) Q_{i}(t)}{\sum_{i=1}^{n}\left(P_{i}(t-1)+P_{i}(t) \lambda(t)\right) Q_{i}(t-1)}
$$

then $\lambda(t)=1 / \Pi(t)$. This equation can be re-arranged to solve for $\lambda(t)$ :

$$
\lambda(t)=\frac{G(t) \sum_{i=1}^{n} Q_{i}(t-1) P_{i}(t-1)-\sum_{i=1}^{n} Q_{i}(t) P_{i}(t-1)}{\sum_{i=1}^{n} Q_{i}(t) P_{i}(t)-G(t) \sum_{i=1}^{n} Q_{i}(t-1) P_{i}(t)}
$$

Now, $\Pi(t)$ is the ratio of the aggregate deflator at time $t$ to the deflator at time $t-1$ (known as the "price relative" for the deflator.) By definition, then, the following equation holds:

$$
\frac{\Pi(t)}{\sum_{i=1}^{n} Q_{i}(t) P_{i}(t)}=\frac{1}{G(t) \sum_{i=1}^{n} Q_{i}(t-1) P_{i}(t-1)}
$$

Multiplying the numerator and denominator of (7) by this value, and re-arranging gives

$$
\lambda(t)=\frac{1-\Pi(t) / H(t)}{\Pi(t)-L(t)}
$$

where $H(t)$ and $L(t)$ are the price relatives for the aggregate Paasche and Laspeyres price indexes. From the fact that the deflator for a Fisher chain aggregate is itself a Fisher aggregate, we know that $H(t) L(t)=\Pi^{2}(t)$. Inserting this gives the required result. The contributions to growth formula is then obtained by subtracting 1 from equation (6).

I am grateful to Chris Ehemann of BEA for providing me with this derivation. See Moulton and Seskin (1999) for further discussion of this contribution formula. 